\title{
Novel Permanent Magnet Motor Drives for Electric Vehicles
}

\author{
C. C. Chan, Fellow, IEEE, K. T. Chau, Member, IEEE; J. Z. Jiang, \\ W. Xia, Student Member, IEEE, Meiling Zhu, and Ruoju Zhang
}

\begin{abstract}
Novel permanent magnet (PM) motor drives have been successfully developed to fulfil the special requirements for electric vehicles such as high power density, high efficiency, high starting torque, and high cruising speed. These PM motors are all brushless and consist of various types, namely rectangular-fed, sinusoidal-fed, surface-magnet, buried-magnet, and hybrid. The advent of novel motor configurations lies on the unique electromagnetic topology, including the concept of multipole magnetic circuit and full slot-pitch coil span arrangements, leading to a reduction in both magnetic yoke and copper, decoupling of each phase flux path, and hence an increase in both power density and efficiency. Moreover, with the use of fractional number of slots per pole per phase, the cogging torque can be eliminated. On the other hand, by employing the claw-type rotor structure and fixing an additional field winding as the inner stator, these PM hybrid motors can further provide excellent controllability and improve efficiency map. In the PM motors, by purposely making use of the transformer EMF to prevent the current regulator from saturation, a novel control approach is developed to allow for attaining high-speed constant-power operation which is particularly essential for electric vehicles during cruising. Their design philosophy, control strategy, theoretical analysis, computer simulation, experimental tests and application to electric vehicles are described.
\end{abstract}

\section{INTRODUCTION}

W ITH the advent of high-energy permanent-magnet (PM) materials such as neodymium-iron-boron ( $\mathrm{Nd}$ $\mathrm{Fe}-\mathrm{B})$ and samarium-cobalt $(\mathrm{Sm}-\mathrm{Co})$, the development of PM motor drives has been accelerated [1]. Apart from their promising applications to industry, PM motor drives are becoming attractive for electric vehicle (EV) applications [2].

By replacing the field winding of $\mathrm{dc}$ motors with permanent magnets, PM dc motors have relatively higher power density and higher efficiency because of the space-saving benefit by permanent magnets and the absence of field losses. However, the principal problem of dc motors, due to their commutators and brushes, makes them less reliable and unsuitable for maintenance-free operation. Thus, PM dc motor drives are less attractive for electric propulsion [3]. Nevertheless, due to their simplicity, they have been accepted for low-power EV applications such as electric bikes and electric tricycles.

By replacing the field winding of conventional synchronous motors with permanent magnets, PM synchronous motors eliminate conventional brushes, slip-rings and field losses. As these motors are essentially synchronous motors, they can

Manuscript received September 13, 1995; revised November 11, 1995.

The authors are with the Department of Electrical \& Electronic Engineering, The University of Hong Kong, Pokfulam, Hong Kong.

Publisher Item Identifier S 0278-0046(96)02365-9. run from a sinusoidal or PWM supply without electronic commutation. On the other hand, by inverting the stator and rotor of PM dc motors, PM brushless dc motors are generated. The most obvious advantage of these motors is the removal of brushes and commutation, leading to eliminate many problems associated with brushes. They are fed by rectangular waveform and employ rotor position feedback to control the commutation. In general, they can be classified as sinusoidalfed and rectangular-fed versions of PM brushless motors [4]. It should be noted that these brushless configurations allow more cross-sectional area for the armature winding and improve the conduction of heat through the frame, thus increasing the electric loading and hence power density. Due to their inherent high power factor and the absence of field losses, they also possess high efficiency, Recently, these PM brushless motor drives have been applied to modern electric vehicles [5]-[8].

In Section II, the special requirements and considerations of EV motor drives are presented. Then, the design philosophy of novel PM motor drives, including both PM brushless and PM hybrid brushless configurations, for modern electric vehicles is described in Section III. Theoretical analysis, control strategy and results of a novel PM brushless motor drive are given in Sections IV, V and VI, respectively.

\section{EV MOTOR DRIVES}

Instead of considering EV motor drives as a subclass of industrial motor drives, they should form an individual class because of the following reasons.

- Their load requirements are fundamentally different. EV motor drives usually require frequent start/stop, high rate of acceleration/deceleration, high-torque low-speed hill climbing and low-torque high-speed cruising, while industrial motor drives are generally optimized at rated conditions for continuous and short-time ratings. Moreover, EV motor drives should be designed according to the driving cycle specification of electric vehicles.

- Their performance requirements are very different. EV motor drives demand both high power density and high efficiency for the reduction of total vehicle weight and the extension of driving range, while industrial motor drives generally need a compromise among power density, efficiency and cost. Increasingly, EV motor drives desire high controllability, high steady-state accuracy and good transient performance for single- or multiple-motor propulsion [9]. 
- Their operating environments are also different. EV motor drives are usually installed in mobile vehicles, while industrial motor drives are generally located in fixed places.

Apart from satisfying the aforementioned special requirements, the design of EV motor drives also depends on the system technology of electric vehicles. From the technological point of view, the following key issues should be considered.

- Single- or multiple-motor configurations: One adopts a single motor to propel the driving wheels, while another uses multiple motors permanently coupled to individual driving wheels. The multiple-motor configuration takes the advantages to reduce the current/power ratings of individual motor drives and simulate differential action electronically. Without using the mechanical differential device, this configuration can provide limited slip action, more space and lighter weight. However, fault tolerance should be incorporated to acquire the reliability of electronic differential action.

- Single- or multiple-speed transmissions: One adopts single-speed fixed gearing, while another uses multiplespeed gear changing. Although the multiple-speed transmission provides the advantage of using conventional motor drives to achieve high starting torque at low gear and high cruising speed at high gear, it suffers from heavy weight, large size, high cost and additional complexity. With the introduction of advanced EV motor drives, the single-speed transmission can overcome these shortcomings, while improving driving smoothness and transmission efficiency.

- Gear ratio or gearless: The use of single-speed transmission with high gear ratio allows $\mathrm{EV}$ motor drives to be designed for high-speed operation, resulting higher power density. The maximum speed is limited by the friction and windage losses as well as transaxle tolerance. On the contrary, all transmission gears can be omitted by directly employing low-speed outer-rotor motor drives for individual driving wheels.

- System voltage: The design of EV motor drives is greatly influenced by the selection of the EV system voltage level. Reasonable high-voltage motor design can be adopted to reduce the cost and size of inverters. If the desired voltage is too high, a large number of batteries will be needed to connect in series, leading to the reduction of interior and luggage spaces, the increase in vehicle weight and cost as well as the degradation of vehicle performances. Since different EV types adopt different system voltage levels, the design of EV motor drives needs to cater for different electric vehicles.

Until now, the development of EV motor drives is still in its crawling stage. In order to enhance the realization of practical electric vehicles, the development must be accelerated.

\section{DESIGN PHILOSOPHY}

Focusing on three major criteria of EV motor drives, namely high power density, high efficiency and wide speed range, the design philosophy is proposed [10]-[12]. Basically, this philosophy consists of two novel approaches. The first approach lies on the development of specially-configured PM brushless motor drives incorporating with a novel control strategy. The second one is to develop specially designed PM hybrid brushless motor drives by incorporating both permanent magnets and the field winding.

\section{A. PM Brushless Motor Drives}

Because of their inherent high power density and high efficiency, PM brushless motor drives have promising applications for EV propulsion. Nevertheless, further development and continual efforts are necessary to fulfil the special requirements of electric vehicles. The novelty of the proposed PM brushless motor drives comprises of both motor design and control strategy. Compared with the conventional PM brushless motor drives, they have the following distinct features.

- There are many poles, and two adjacent poles make up a pair of poles so that the flux paths of different polepairs are independent. This multipole magnetic circuit arrangement enables to reduce the magnetic iron yoke, resulting in the reduction of volume and weight. Moreover, because of the independence of flux paths, these motors are inherently phase decoupling.

- Since the coil span of stator windings is designed to be equal to the slot pitch, the overhanging part of the coil can be significantly reduced, thus resulting in the saving of copper as well as the further reduction of volume and weight.

- By using the fractional number of slots per pole per phase, the magnetic force between the stator and rotor at any rotating position is uniform, thus eliminating the cogging torque which usually occurs in the conventional PM brushless motor drives.

- Due to the phase-decoupling nature, the dynamic performance of these motor drives are inherently excellent. However, conventional field-weakening control for constant-power operation becomes inapplicable. Therefore, a novel control strategy is developed which employs the transformer EMF to counteract the rotational EMF for constant-power operation at high speeds.

- Permanent magnets can either be mounted on the rotor surface or buried inside the rotor circuit. The surfacemagnet type has the advantage of simplicity. Because of the permeability of permanent magnets is similar to that of air, it possesses a large effective air-gap. On the other hand, the buried-magnet type has the advantage of mechanical integrity because the permanent magnets are physically protected. Moreover, flux-focusing 'arrangement can be employed to strengthen the air-gap flux density:

- These PM brushless motors can be either sinusoidalfed or rectangular-fed. The sinusoidal-fed type has the advantage of smooth torque due to the interaction of sinusoidal current and sinusoidal flux. On the other hand, the interaction of rectangular current and rectangular flux can produce a large torque for the same rms values. 


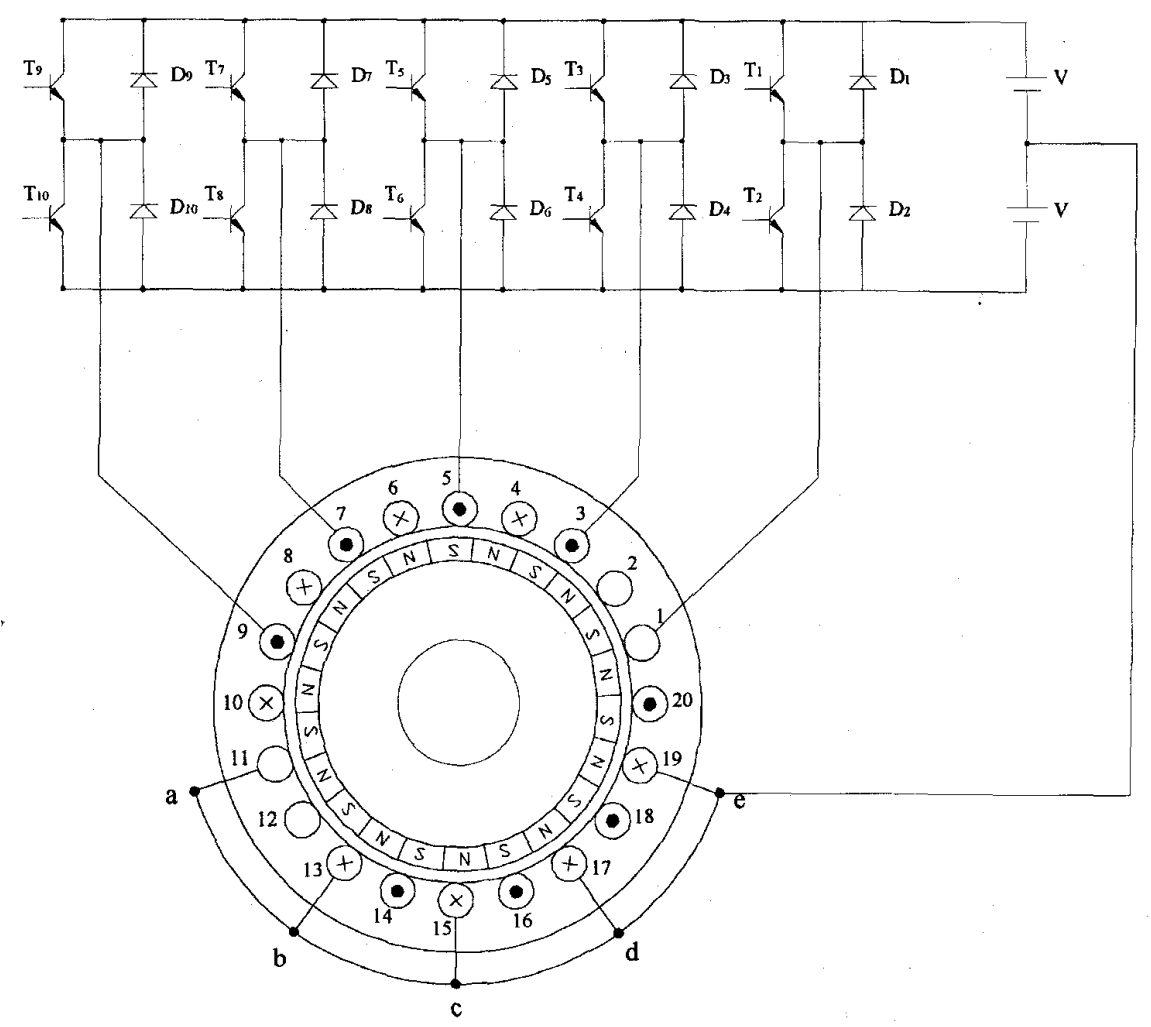

Fig. 1. PM brushless configuration with phase decoupling.

As shown in Fig. 1, the schematic diagram of a 5-phase 22pole phase-decoupling surface-mounted PM brushless motor drive is used for exemplification. The corresponding theoretical analysis, control strategy, simulation and experimental results are described in the following sections.

\section{B. PM Hybrid Brushless Motor Drives}

Recently, a new research direction has been identified on the development of PM hybrid brushless motor drives. The uniqueness of PM hybrid brushless motors is due to the existence of both permanent magnets and the field winding. Permanent magnets are generally integrated into the rotor, while the field winding is usually fixed at a stationary holder. Without employing any special control strategies, these motor drives inherently possess wide speed range operation. The key is due to the fact that the motor air-gap flux can be flexibly controlled by adjusting the dc field current. It should be noted that this flexible field control, particularly field-weakening at high speeds, is highly desirable for constant-power operation of electric vehicles.

As shown in Fig. 2, a novel PM hybrid brushless motor drive is proposed for EV propulsion. It has a unique structure which comprises of the claw-type rotor, stationary field winding, and stator. Permanent magnets are integrated into the rotor, while the field winding and its holder are located at a stationary annular region formed by the inner and outer parts of the rotor. Thus, the components of air-gap flux, respectively produced by permanent magnets and the field windings, are magnetically shunt in nature. The advantages and special features of this motor drive are summarized as follows.

- By adopting the unique claw-type rotor structure, the leakage flux can be minimized and the construction becomes compact. Moreover, by fixing the field winding as an inner stator, the motor axial length can be shortened and the material consumption can be reduced.

- Due to the existence of both permanent magnets and the field winding, the motor can be designed to achieve higher air-gap flux density and hence higher power density. Increasingly, the mounting of permanent magnets adopts the flux-focusing arrangement, which allows the air-gap flux density being higher than the operating flux density of individual permanent magnets.

- By controlling the direction and magnitude of the dc field current, the air-gap flux can be flexibly adjusted, hence the torque-speed characteristics can be easily shaped to meet the special requirements for EV propulsion. Particularly, by using field current control to weaken the air-gap flux produced by permanent magnets, the speed range for constant-power operation can be significantly extended.

- By proper controlling the applied voltage and dc field current, the efficiency map of the motor drive can be optimized throughout the whole operating range. Thus, the efficiency at those operating regions for EV propulsion, such as high-torque low-speed hill climbing and low-torque high-speed cruising, can be improved.

Detailed theoretical analysis, control strategy, simulation and experimental results of this PM hybrid brushless motor 
drive are omitted, and will form the substance of our next publication.

\section{THEORETICAL ANALYSIS}

\section{A. Electromagnetic-Field Analysis}

Since the proposed PM brushless motor has a special configuration, the design and optimization process employs electromagnetic-field analysis [14]. The procedure can be summarized as follows.

- Initialize the motor configuration and geometry.

- Generate meshes automatically for the region of interest.

- Apply the finite element method (FEM) for electromagnetic-field analysis.

- Evaluate the motor parameters and performances.

- Modify the motor geometry iteratively.

Due to the semiperiodic motor configuration, the region of interest is shown in Fig. 3. The corresponding Maxwell's equation is expressed as

$$
\frac{\partial}{\partial x}\left(\nu \frac{\partial \mathbf{A}}{\partial x}\right)+\frac{\partial}{\partial y}\left(\frac{\partial \mathbf{A}}{\partial y}\right)=-\mathbf{J}_{z}-\nu \frac{\partial \mathbf{M}_{y}}{\partial x}+\nu \frac{\partial \mathbf{M}_{x}}{\partial y}
$$

where $\mathbf{A}$ is the magnetic vector potential, $\mathrm{J}_{z}$ is the current density in $z$ direction, $\nu$ is the reluctivity, $\mathbf{M}_{x}$ and $\mathbf{M}_{y}$ are the magnetic polarization in $x$ and $y$ directions. The magnetic flux density $\mathbf{B}$ can be obtained as

$$
\mathbf{B}=\operatorname{rot} \mathbf{A}
$$

where the $x$ and $y$ components are expressed as

$$
\begin{aligned}
& \mathbf{B}_{x}=\frac{\partial \mathbf{A}}{\partial y} \\
& \mathbf{B}_{y}=-\frac{\partial \mathbf{A}}{\partial x} .
\end{aligned}
$$

Based on the region of interest, the boundary conditions are given by

$$
\begin{aligned}
& \left.\mathbf{A}\right|_{T 1}=\left.\mathbf{A}\right|_{T 2}=0 \\
& \left.\mathbf{A}\right|_{N 1}=-\left.\mathbf{A}\right|_{N 2}
\end{aligned}
$$

The resulting magnetic flux density distribution is shown in Fig. 4. Based on these results, the motor geometry can be adjusted as desired to achieve optimization.

\section{B. Mathematical Equations}

Since the motor possesses the property of phase decoupling, the mutual inductance between phase windings is negligible. Thus, the voltage equation of the motor with $m$ phases can be expressed as

$$
\begin{aligned}
v_{j}\left(\omega t+\theta_{0}-\frac{(j-1) \pi}{m}\right)= & R i_{j}\left(\omega t+\theta_{0}-\frac{(j-1) \pi}{m}\right) \\
& +L p i_{j}\left(\omega t+\theta_{0}-\frac{(j-1) \pi}{m}\right) \\
& +e_{j}\left(\omega t-\frac{(j-1) \pi}{m}\right)
\end{aligned}
$$

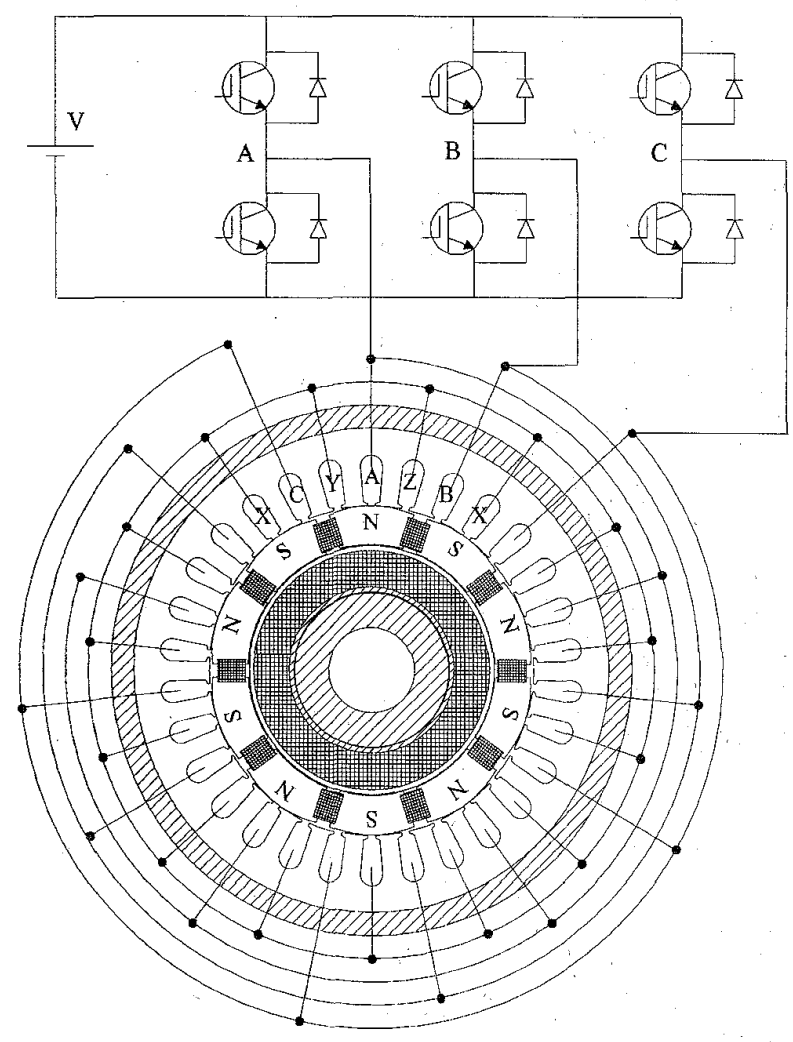

(a)

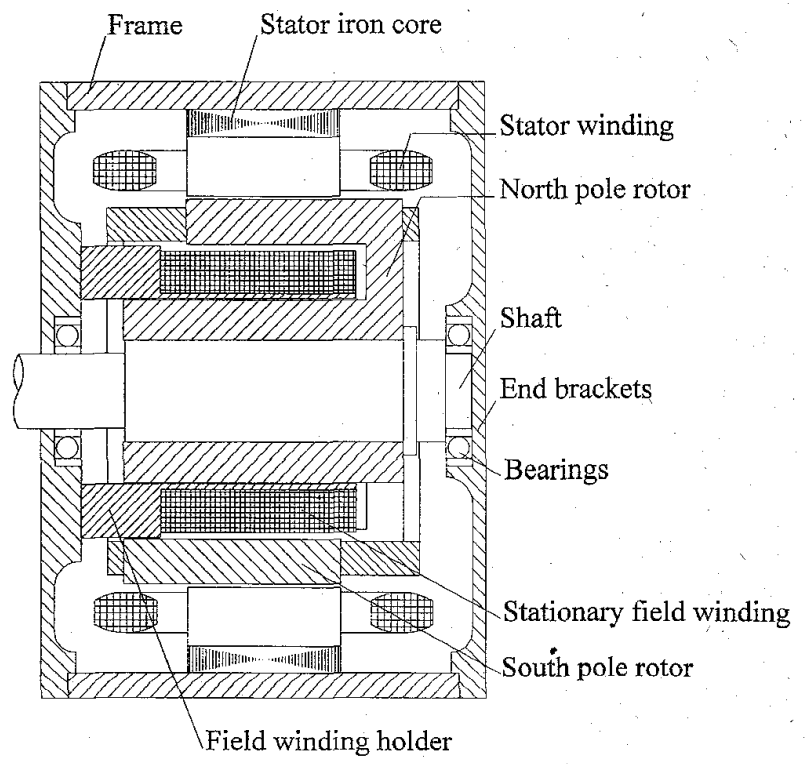

(b)

Fig. 2. PM hybrid brushless configuration with claw-type rotor. (a) Diagram. (b) Structure.

where $j=1,2, \ldots, m, v_{j}$ is the applied voltage, $R i_{j}$ is the resistance voltage drop, $L p i_{j}$ is the induced EMF due to the transformer effect, and $e_{j}$ is the induced EMF due to the rotational effect. The value of inductance $L$ is determined by using the aforementioned electromagnetic-field analysis. Based 


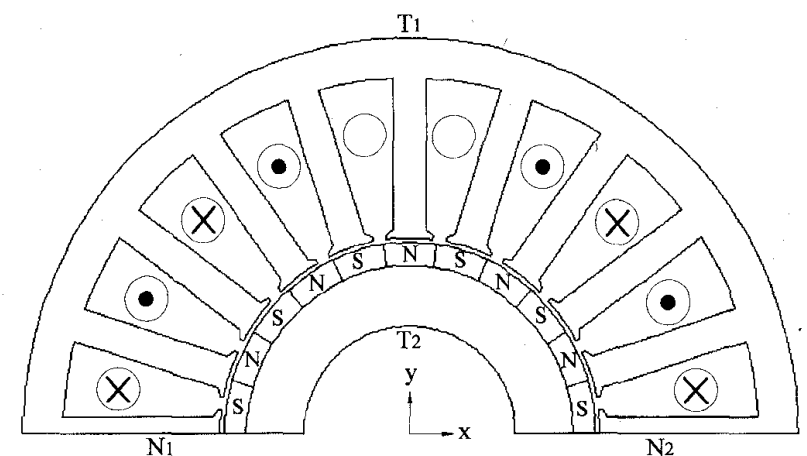

Fig. 3. Region for electromagnetic-field analysis.

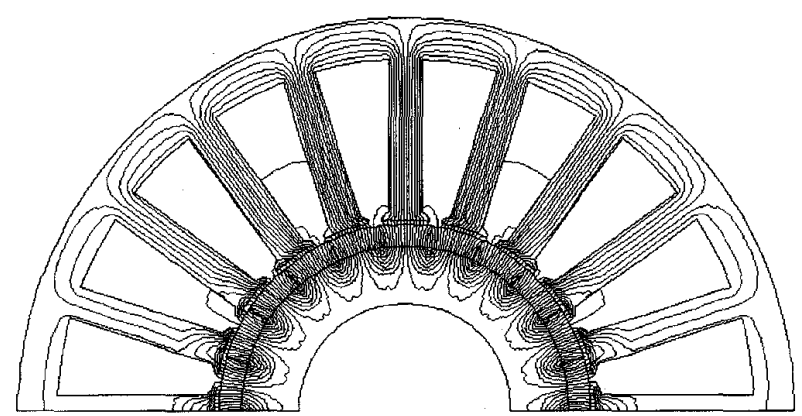

(a)

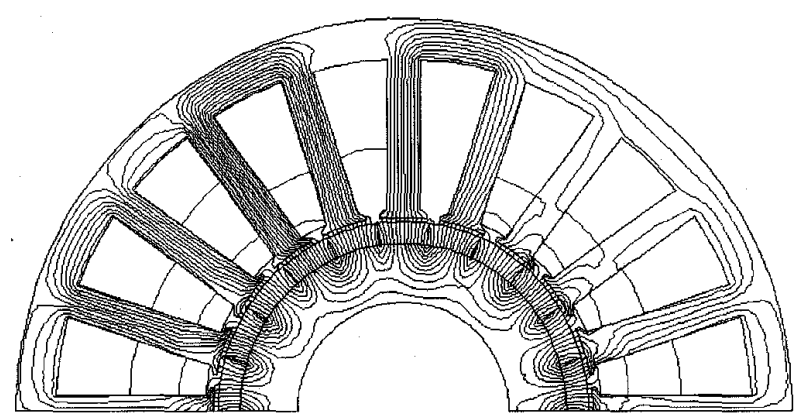

(b)

Fig. 4. Magnetic flux density distribution. (a) No-load. (b) Full-load.

on the Faraday law, the rotational EMF can be expressed as

$$
e_{j}=\frac{d \lambda_{j}}{d \theta} \frac{d \theta}{d t}=\frac{d \lambda_{j}}{d \theta} \omega
$$

where $\lambda_{j}$ is the flux linkage in the $j$-th phase winding due to permanent magnets, $\theta$ is the angle between the field and stator winding axes, and $\omega$ is the angular speed. It should be noted that $d \lambda_{j} / d \theta$ is the well-known EMF coefficient $C_{e j}$ which is particularly useful for dynamic analysis. Hence, the electromagnetic torque $T_{e}$ is given by

$$
\begin{aligned}
T_{e}(\omega t)= & \frac{1}{\omega} \sum_{j=1}^{m} e_{j}\left(\omega t-\frac{(j-1) \pi}{m}\right) \\
& \times i_{j}\left(\omega t+\theta_{0}-\frac{(j-1) \pi}{m}\right) .
\end{aligned}
$$

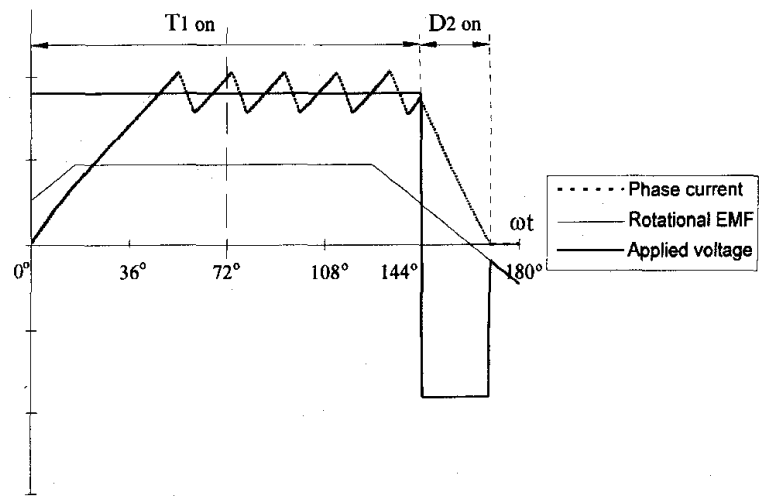

(a)

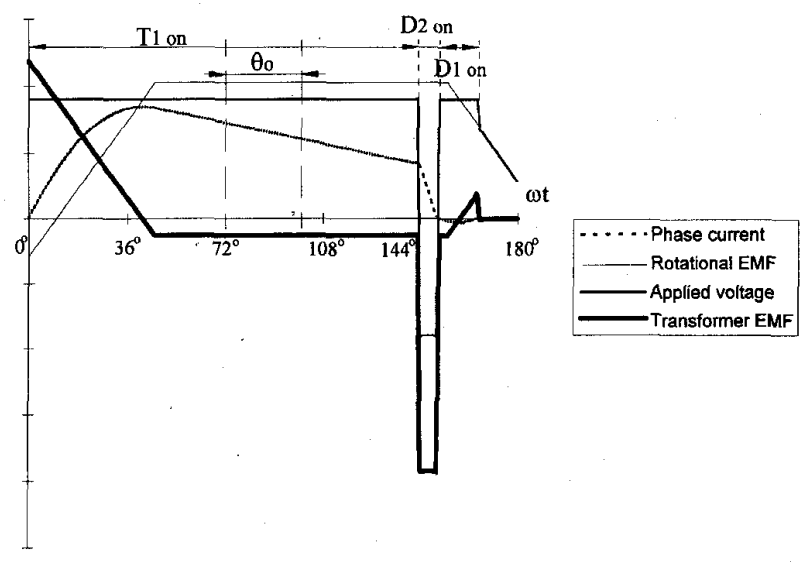

(b)

Fig. 5. Typical waveforms. (a) Constant-torque operation. (b) Constant-power operation.

Having derived the electromagnetic torque, the torque equation of the motor can be expressed as

$$
T_{e}(\omega t)-T_{l}-B \omega(t)=J p \omega(t)
$$

where $T_{l}$ is the load torque, $B$ is the damping coefficient, and $J$ is the moment of inertia. Thus, by making use of (1)-(10), the dynamic performance of the motor can be determined.

\section{Control Strategy}

The control strategy of the motor drive consists of two schemes, namely hysteresis current control and advanced conduction angle control, respectively for constant-torque operation at speeds below the base speed and constant-power operation at speeds above the base speed.

Fig. 5(a) shows typical waveforms of the phase current, rotational EMF and applied voltage during constant-torque operation. Within the conduction period of $T_{1}$, the applied voltage is always larger than the rotational EMF and they are always in phase. Thus, the phase current increases gradually and is eventually limited to swing within the desired hysteresis band. This hysteresis current control scheme has been widely adopted for constant-torque operation of PM brushless motor drives. 


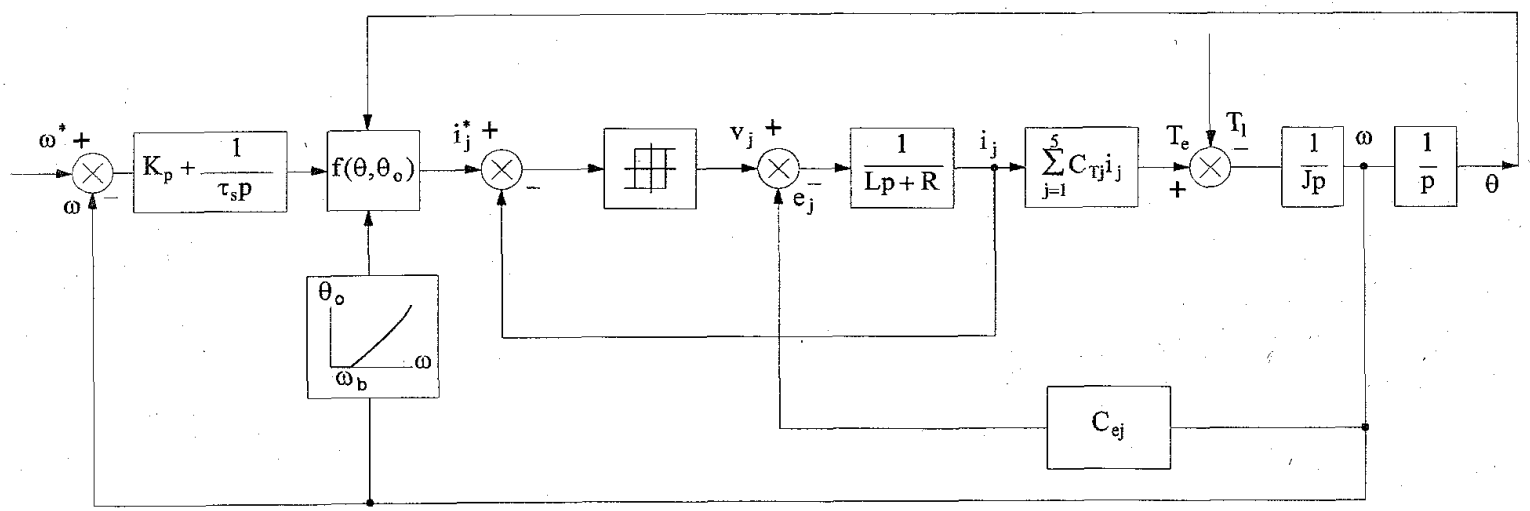

Fig. 6. Control block diagram.

When the speed is above the based speed, the rotational EMF increases rapidly in such a way that constant-power operation can no longer be maintained at high speeds. Conventionally, in order to allow PM brushless motor drives achieving high-speed constant-power operation, field-weakening control incorporating with coordinate transformation is adopted. The key of this control approach is to employ the field component of phase current to weaken the air-gap field produced by permanent magnets, hence reducing the rotational EMF. However, this approach can only be applied to conventional sinusoidal-fed PM brushless motor drives. It is ill-suited for the proposed motor drive because of its rectangular-fed and phasedecoupling features. Although the first feature can theoretically be handled by using Fourier analysis to express the rectangular wave into the fundamental and harmonic sinusoidal waves, the second feature makes conventional field-weakening control inapplicable.

To deal with this problem, a novel control approach is proposed which allows all PM brushless motor drives, including conventional, phase-decoupling, sinusoidal-fed and rectangular-fed types, achieving high-speed constant-power operation. The key is to purposely employ the transformer EMF to counteract the rotational EMF which is even larger than the applied voltage at high speeds. This transformer EMF, proportional to the derivative of phase current, is controlled by advancing the conduction period in such a way that it leads the rotational EMF by a spatial angle $\theta_{0}$, so-called the advanced conduction angle. As shown in Fig. 5(b), when the applied voltage is larger than the rotational EMF, the phase current increases. Thus, the transformer EMF is positive which indicates that energy is stored in the phase winding. When the rotational EMF becomes larger than the applied voltage, the phase winding begins to release energy and the phase current decreases gradually. Since the corresponding transformer EMF is negative, it assists the applied voltage to counteract the rotational EMF. Therefore, by varying the advanced conduction angle, the phase current waveform can be shaped, hence the transformer EMF can be controlled to counteract the rotational EMF, preventing the current regulator from saturation. This phenomenon is the key point to allow all types of PM brushless motor drives achieving constant-power operation at high speeds.

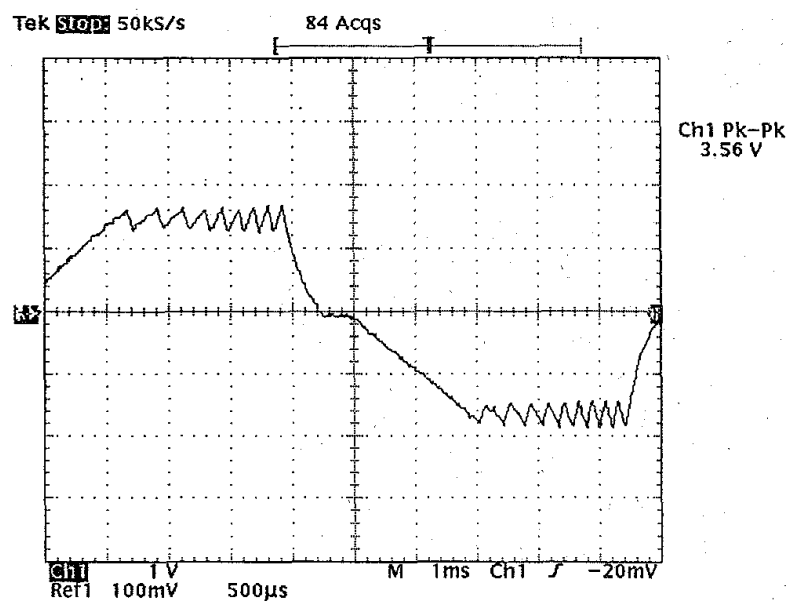

(a)

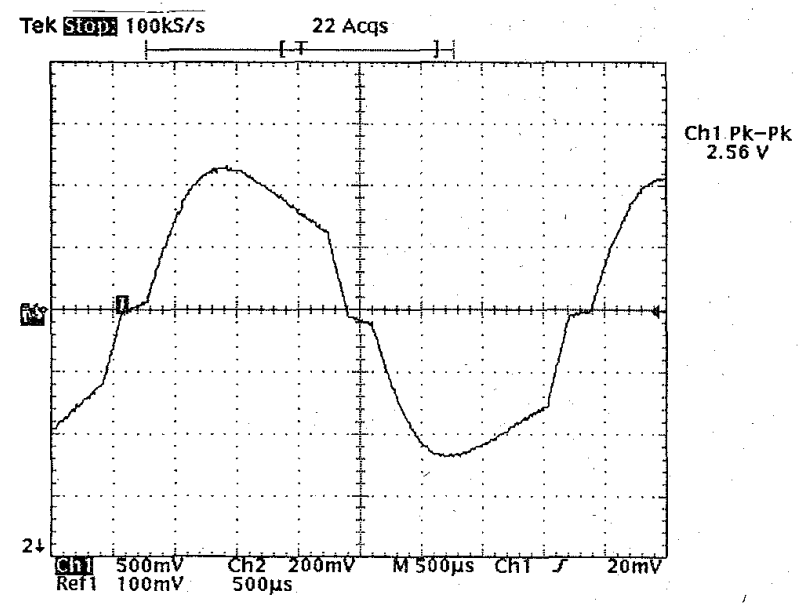

(b)

Fig. 7. Measured current waveforms. (a) Constant-torque operation at 500 rpm (20A/div, $1 \mathrm{~ms} / \mathrm{div})$. (b) Constant-power operation at $1500 \mathrm{rpm}(10 \mathrm{~A} / \mathrm{div}$, $500 \mu \mathrm{s} / \mathrm{div})$.

Fig. 6 shows the closed-loop control block diagram of the proposed motor drive, in which both hysteresis current control and advanced conduction angle control are incorporated. By using the PI regulator, the error between the speed reference $\omega^{*}$ and speed feedback $\omega$ is used to deduce the magnitude 
TABLE I

PARAMETERS FOR THE MOTOR

\begin{tabular}{ll}
\hline Rated power & $1.5 \mathrm{~kW}$ \\
Rated voltage & $2 \times 48 \mathrm{~V}$ \\
Base speed & $500 \mathrm{rpm}$ \\
No. of phases & 5 \\
No. of poles & 22 \\
No. of slots & 20 \\
No. of coils & 10 \\
Winding type & Single layer \\
Slot pitch & 1 slot \\
Resistance per phase & $0.054 \Omega$ \\
Self-inductance per phase & $1.29 \mathrm{mH}$ \\
Magnet material & $\mathrm{Nd}-\mathrm{Fe}-\mathrm{B}$ \\
\hline
\end{tabular}

of current reference. When $\omega$ is lower than or equal to the base speed $\omega_{b}$, the advanced conduction angle $\theta_{0}$ is zero. On the other hand, it operates with positive $\theta_{0}$ when $\omega$ is higher than $\omega_{b}$. The corresponding value of $\theta_{0}$ is determined by using computer simulation. Making use of $\theta_{0}$ and the position feedback $\theta$, the $j$-th phase current reference $i_{j}^{*}$ can be obtained. By comparing with the current feedback $i_{j}$ and then feeding into the hysteresis current controller, the applied voltage $v_{j}$ can be deduced accordingly. Making use of (8), the rotational EMF $e_{j}$ is related to $\omega$ by the EMF coefficient $C_{e j}$. Then, $i_{j}$ is generated by using (7). Based on (9) and rewriting the relationship between $e_{j}$ and $\omega$ by the torque coefficient $C_{T j}$, the electromagnetic torque $T_{e}$ can be determined. Finally, both $\omega$ and $\theta$ are resulted from (10).

\section{RESULTS}

An experimental PM brushless motor drive has been built for verification. The corresponding motor parameters are listed in Table I. When the motor drive runs at the base speed of 500 $\mathrm{r} / \mathrm{min}$, hysteresis current control is adopted for constant-torque operation. The corresponding measured current waveform is shown in Fig. 7(a), as expected, which agrees with the theoretical waveform shown in Fig. 5(a). Moreover, when the motor drive runs at the triple base speed of $1500 \mathrm{r} / \mathrm{min}$, advanced conduction angle control is used for constant-power operation. With the advanced conduction angle of $60^{\circ}$, the corresponding measured current waveform is shown in Fig. 7(b). Again, it agrees with the waveform shown in Fig. 5(b).

In order to testify the dynamic performance of the motor drive, the measured speed and current responses are recorded. Fig. 8(a) shows the no-load starting performance from standstill to the base speed of $500 \mathrm{r} / \mathrm{min}$. It can be found that the motor drive responds quickly and takes only $0.35 \mathrm{~s}$ to reach the desired speed without steady-state error. Moreover, Fig. 8(b) shows the dynamic performance under a sudden change from no-load to full-load at the base speed of $500 \mathrm{r} / \mathrm{min}$. It can be seen that the transient drop in speed is very insignificant and the speed regulation is excellent.

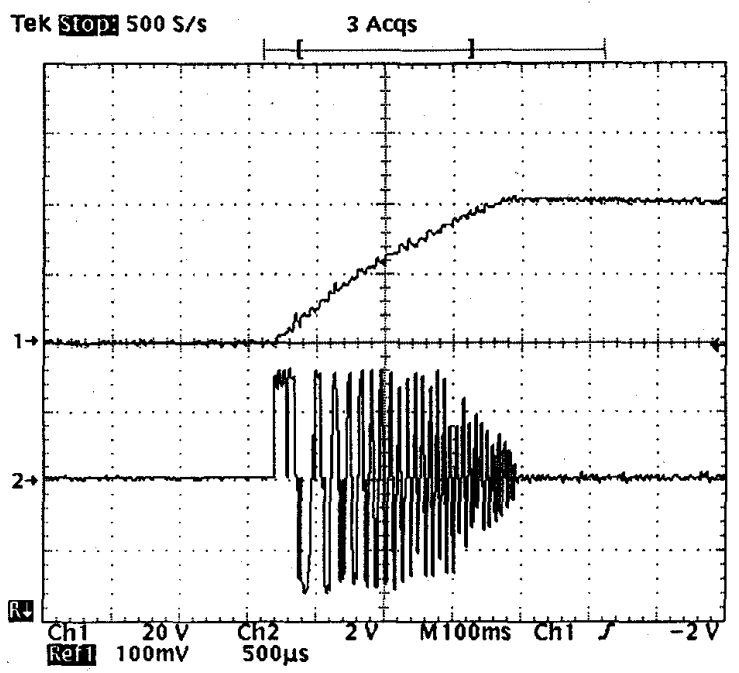

(a)

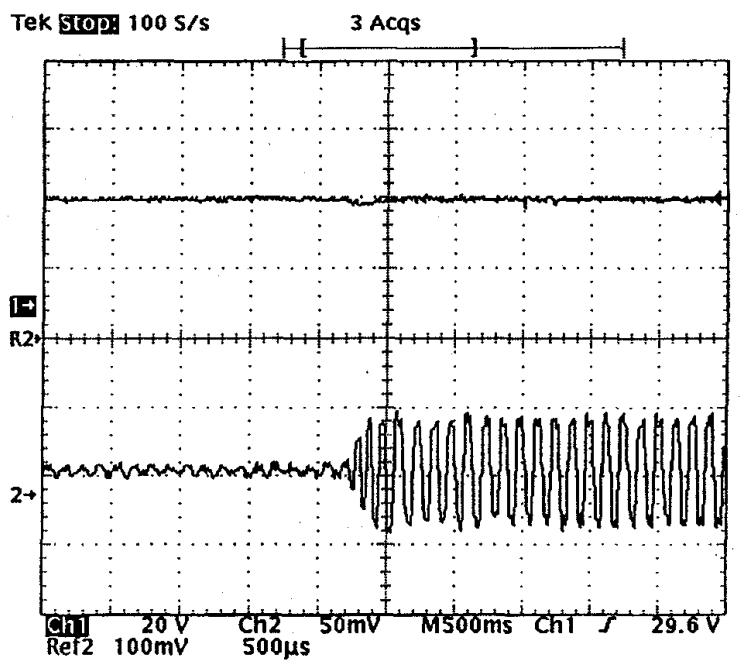

(b)

Fig. 8. Measured speed (upper trace) and current (lower trace) responses. (a) No-load starting $(250 \mathrm{r} / \mathrm{min} / \mathrm{div}, 40 \mathrm{~A} / \mathrm{div}, 100 \mathrm{~ms} / \mathrm{div})$. (b) Sudden change from no-load to full-load $(250 \mathrm{r} / \mathrm{min} / \mathrm{div}, 36 \mathrm{~A} / \mathrm{div}, 500 \mathrm{~ms} / \mathrm{div})$.

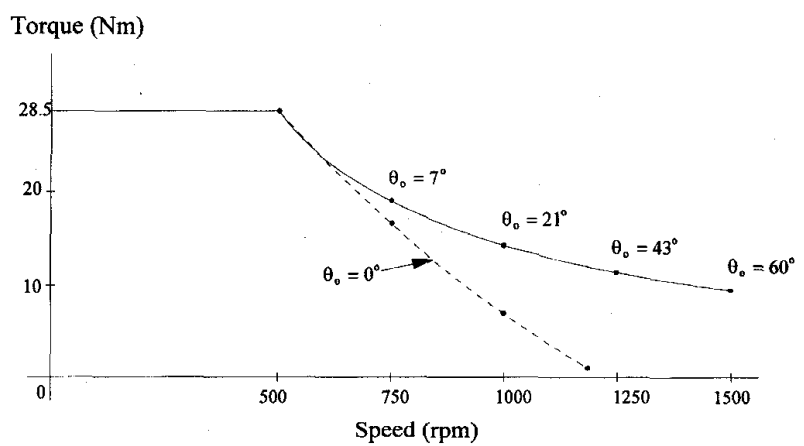

Fig. 9. Measured advanced conduction angles for constant-power operation.

Fig. 9 shows the corresponding advanced conduction angles, from $0^{\circ}$ to $60^{\circ}$, for the experimental motor drive to operate at constant rated power from the base speed of 500 


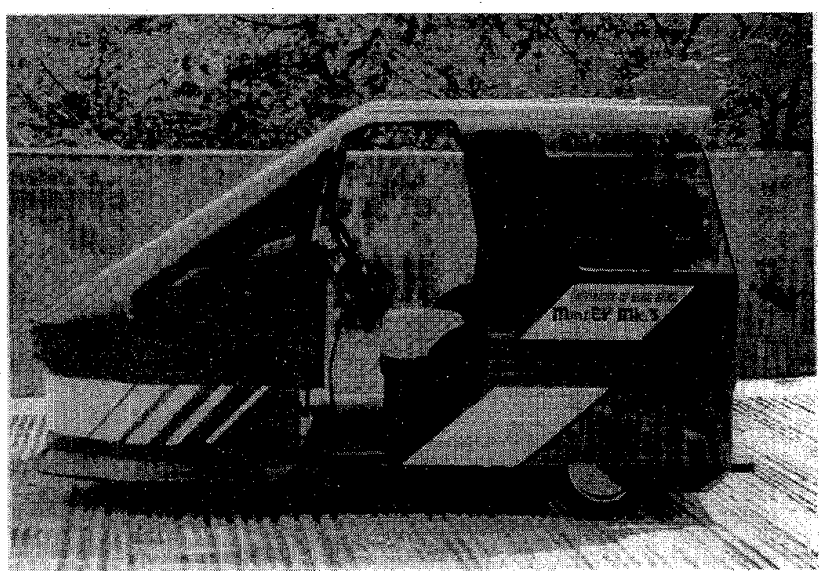

(a)

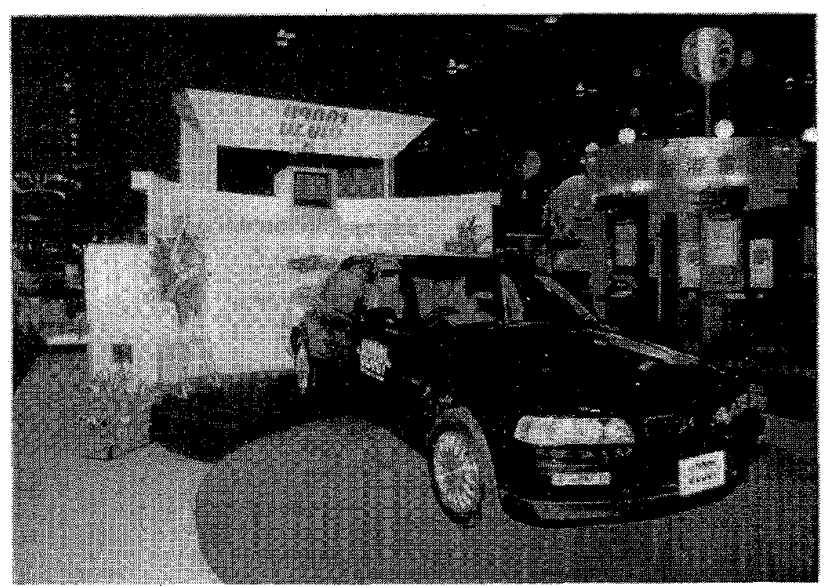

(b)

Fig. 10. Experimental electric vehicles. (a) Mark 3. (b) U2001.

TABLE $\Pi$

EV SPECIFICATIONS

\begin{tabular}{lll}
\hline & Mark 3 & U2001 \\
\hline Curb weight & $403 \mathrm{~kg}$ & $1973 \mathrm{~kg}$ \\
Battery weight & $288 \mathrm{~kg}$ & $792 \mathrm{~kg}$ \\
Payload weight & $200 \mathrm{~kg}$ & $250 \mathrm{~kg}$ \\
Maximum speed & $30 \mathrm{~km} / \mathrm{h}$ & $110 \mathrm{~km} / \mathrm{h}$ \\
Acceleration & $8 \mathrm{~s}(0-20 \mathrm{~km} / \mathrm{h})$ & $6.3 \mathrm{~s}(0-48 \mathrm{~km} / \mathrm{h})$ \\
Range per charge & $70 \mathrm{~km}(20 \mathrm{~km} / \mathrm{h})$ & $176 \mathrm{~km}(88 \mathrm{~km} / \mathrm{h})$ \\
Climbing capability & $15 \%$ & $30 \%$ \\
\hline
\end{tabular}

$\mathrm{r} / \mathrm{min}$ to $1500 \mathrm{r} / \mathrm{min}$. It can be verified that with the use of advanced conduction angle control, the proposed motor drive can successfully achieve constant-power operation up to the triple base speed. Furthermore, without employing the proposed control scheme, it can be found that the corresponding torque speed curve (dotted line) has a narrow operating range above the base speed.

\section{EV APPLICATIONS}

The proposed PM brushless motor drive has been applied to an experimental mini EV, namely the Mark 3 as shown in
Fig. 10(a). Its specification is listed in Table II. The field test shows that the corresponding performance is very satisfactory. Thus, a similar motor drive with output power of $30 \mathrm{~kW}$ is under development which will be installed in a modern passenger EV, namely the U2001 as shown in Fig. 10(b). As listed in Table II, the specification of U2001 can fully fulfil our expectations on electric vehicles.

\section{CONCLUSION}

The concept of classifying EV motor drives to be different from industrial motor drives is presented. Based on their special requirements and considerations, especially high power density, high efficiency and wide speed range, the design philosophy of novel PM motor drives, including both PM brushless and PM hybrid brushless configurations, is described. The novelty of PM brushless configuration lies on the unique electromagnetic topology and winding connections, leading to increase both power density and efficiency as well as eliminating the cogging torque. Increasingly, a novel advanced conduction angle control approach is developed which allows all PM brushless motor drives, including conventional, phasedecoupling, sinusoidal-fed, rectangular-fed, surface-magnet, and buried-magnet types, for achieving high-speed constantpower operation during EV cruising. On the other hand, by employing the claw-type rotor and fixing the stationary field winding as the inner stator, a novel PM hybrid brushless motor drive is proposed which possesses the advantages of excellent controllability and optimized efficiency map.

\section{REFERENCES}

[1] M. A. Rahman and G. R. Slemon, "Promising applications of neodymium boron iron magnets in electrical machines," IEEE Trans. Magn., vol. 21, pp. 1712-1716, 1985.

[2] C. C. Chan, "Overview of electric vehicle technology," IEEE Proc., vol. 81 , pp. 1202-1213, 1993.

[3] C. C. Chan and K. T. Chau, "Advanced ac propulsion systems for electric vehicles," in Proc. Int. Symp. Automotive Technol., Automat. (ISATA), Florence, Italy, 1991, pp. 119-125.

[4] T. J. E. Miller, Brushless Permanent-Magnet and Reluctance Motor Drives. New York: Oxford University Press, 1989.

[5] B. K. Bose and P. M. Szczesny, "Microcomputer-based control and simulation of an advanced IPM synchronous machine drive system for electric vehicle propulsion," IEEE Trans. Ind. Electron., vol. 35, pp. 547-559, 1988.

[6] C. C. Chan, W. S. Leung and K. T. Chau, "A new permanent magnet motor drive for mini electric vehicles," in Proc. Int. Electric Vehicle Symp. (EVS), Hong Kong, 1990, pp. 165-174.

[7] C. C. Chan, J. Z. Jiang, G. H. Chen, X. Y. Wang, and K. T. Chau, "A novel polyphase multipole square-wave permanent magnet motor drive for electric vehicles," IEEE Trans. Ind. Applicat, vol. 30, pp. 1258-1266, 1994.

[8] C. C. Chan, R. Zhang, K. T. Chau, and J. Z. Jiang, "A novel permanent magnet hybrid motor for electric vehicles," in Proc. Chinese Int. Conf. Elec. Mach. (CICEM), Hangzhou, China, 1995, pp. 1-6.

[9] C. C. Chan and K. T. Chau, "Electric vehicle technology-An overview of present status and future trends," in Proc. Int. Elec Vehicle Symp. (EVS), Florence, Italy, 1992, no. 1.02, pp. 1-12.

[10] C. C. Chan, J. Z. Jiang, G. H. Chen; and X. Y. Wang, "A novel high power density permanent magnet variable-speed motor," IEEE Trans. Energy Conversion, vol. 8, pp. 297-303, 1993.

[11] C. C. Chan, J. Z. Jiang, G. H. Chen, and K. T. Chau, "Computer simulation and analysis of a new polyphase multipole motor drive," IEEE Tran. Ind. Electron., vol. 40, pp. 570-576, 1993.

[12] C. C. Chan, J. Z. Jiang, W. Xia, and K. T. Chau, "Novel wide range speed control of permanent magnet brushless motor drives," in Proc. Int. Power Electron., Drive Syst. Conf. (PEDS), Singapore, 1995, pp. $780-785$. 
[13] P. Zhou, M. A. Rahman, and M. A. Jabbar, "Field circuit analysis of permanent magnet synchronous motors," IEEE Trans. Magn., vol. 30, pp. $1350-1359,1994$.

[14] C. C. Chan and K. T. Chau, "Finite element method based electrical machine design using distributed computing," Int. J. Computers, Ind., vol. 17, pp. 367-374, 1991.

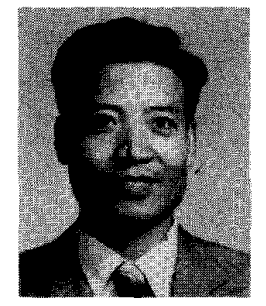

J. Z. Jiang was born in Jiangsu, China, on October 11, 1939. He received the B.E.E. and M.E.E. degrees from Shanghai Jiao-Tong University in 1962 and 1965 , respectively. He obtained the Dr.-Ing. degree from the Technical University of Braunschweig, Germany, in 1988.

$\mathrm{He}$ is Professor of Electrical Engineering at Shanghai University of Technology. His research interests are in high-performance, variables-speed drives, electric machine design, numerical analysis of electromagnetic fields in electric machinery, the dynamic modeling of machines, and their associated power electronics. He has published over 20 papers, and has two patents in these fields.

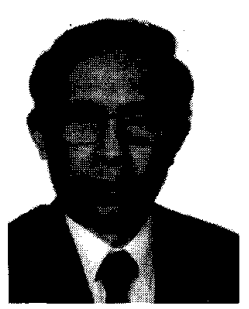

C. C. Chan (F'92) was a Visiting Professor at several well known universities, including the University of California at Berkeley, and was awarded the Hon.D.Sc. degree from the University of Odessa.

He started his professional electrical engineering career in 1959 . He has been working 11 years in industry and 24 years in academic institutions. He is now the endowed Honda Professor and Head of Department of Electrical \& Electronic Engineering at the University of Hong Kong. He is also the Director of the International Research Center for Electric Vehicles. He has published 4 books and over 100 papers on electrical engineering.

Prof. Chan holds over 20 posts on international committees, and serves as Consultant to several organizations in Hong Kong and the U.S.A. He is also a Fellow of IEE and HKIE, Chairman of an IEEE Technical Committee, and is listed in International Leaders of Achievement, Men of Achievement, Who's Who in Australasia and the Far East. He is the co-founder of the World Electric Vehicle Association, and is known as one of the three wise men in the international electric vehicle community.

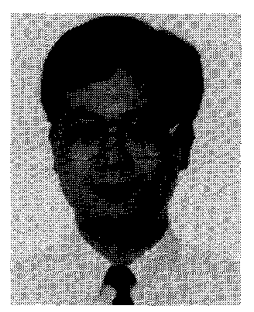

K. T. Chau (M'89) received the first-class honors B.Sc.(Eng.), M.Phil., and Ph.D. degrees al in electrical and electronic engineering from the University of Hong Kong in 1988, 1991, and 1993 , respectively.

From 1990 to 1994, he worked as Lecturer in the Department of Electrical Engineering at the Hong Kong Polytechnic University. Since 1995, he has been with the Department of Electrical \& Electronic Engineering, the University of Hong Kong. His research interests include advanced motor drives, electric vehicles, and power electronics. He has published over 50 refereed technical papers and several industrial reports.

Dr. Chau was the recipient of the Sir Edward Youde Memorial Fellowships in $1988-89$ and $1989-90$.

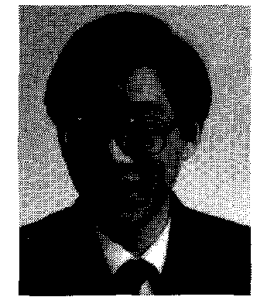

W. Xia (S'95) was born in Shanghai, China, on June 16 1965. He received the B.Sc.(Eng.) and the M.Sc.(Eng.) degrees both in electrical engineering from Shanghai University of Technology in 1988 and 1991, respectively. He currently is a Ph.D. candidate in the Department of Electrical \& Electronic Engineering, the University of Hong Kong.

He had been with Shanghai University of Technology, Shanghai, China from 1991 to 1992 . His research interests include advanced permanent magnet motor drives, motor drive system analysis and design, and electric vehicles. He has published about 10 technical papers in these fields.

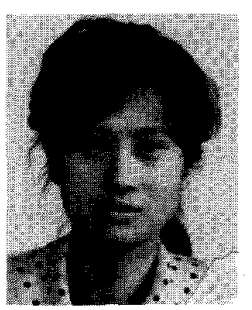

Meiling Zhu received the B.S. and M.S. degrees, both in electrical engineering, from Shanghai University of Technology in 1983 and 1986, respectively. She is currently a Ph.D. research student at the University of Hong Kong.

From 1988 to 1994, she was a lecturer at Shanghai University of Technology. Her teaching and research areas are microcomputer applications in industrial real-time control.

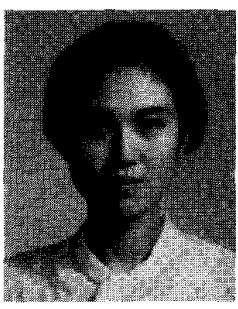

Ruoju Zhang was born in Tianjin, China, in 1967. She received the Bachelor and Master degrees in electrical engineering from Tsinghua University, Beijing, China, in 1990 and 1993, respectively. Currently she is working toward the Ph.D. degree at the University of Hong Kong.

After graduation from Tsinghua University, she worked at Beijing Automatic College as an engineer. Her research interests are $\mathrm{CAD}$, control methods and power electronics in relation to motors and their drive systems, especially in permanent magnet hybrid motors for electric vehicle applications. 